\title{
UMA ALTERNATIVA SUBESTIMADA: A AMÉRICA E OS LIMITES DA TEORIA CRÍTICA ${ }^{1}$
}

\author{
HANS JOAS ${ }^{2}$
}

Desde os anos sessenta, tem sido concedida à "Teoria Crítica" da Escola de Frankfurt grande atenção, tanto na Alemanha Ocidental quanto, em uma extensão crescente, nos Estados Unidos. Trata-se de mais do que apenas uma questão de ter encontrado a "mensagem na garrafa" - como Max Horkheimer e Theodor Adorno gostavam de chamar a teoria deles. O gênio daquela garrafa, de fato, cresceu em proporções muito intimidadoras. Uma opinião comum hoje é de que a “Teoria Crítica” representa a própria incorporação de um programa de pesquisa social interdisciplinar - que detém a espinha dorsal teórica, provê um diagnóstico de nossos tempos e, ao mesmo tempo, contém temas centrais de um Marxismo Ocidental não estalinista e da psicanálise (e, certamente, da crítica da razão, amplamente discutida hoje) que são verdadeiramente dignos de preservação. A pesquisa em história da ciência confirma muito pouco de tal ponto de vista. Em vez disso, traz à tona quão cedo o programa de uma pesquisa social interdisciplinar foi abandonado pela Escola de Frankfurt e quão pouco um diagnóstico de nosso tempo, próximo à realidade política daquele período, foi realmente feito $^{3}$. Em retrospecto, mesmo os principais representantes da "Teoria Crítica" consideraram seus trabalhos como fragmentos, se não como um fracasso; eles certamente não os consideraram como exemplos para as gerações seguintes. Não obstante, a imagem paliativa tem cada vez mais assumido uma vida própria e evoluiu para um fato social que é agora frequentemente tomado como ponto de orientação. Outras abordagens ocidentais do Marxismo que não têm contato, ou o tem apenas superficialmente, com a Escola de Frankfurt foram subsumidas sob o rótulo, cada vez mais usado vagamente, de "Teoria Crítica". Na Alemanha, a linha de frente oblíqua da famosa "disputa em torno do positivismo" [Positivismusstreit] nas ciências sociais durante os anos sessenta derivou em grande extensão daquela imagem paliativa. Nos Estados Unidos, a exaltação da "Teoria Crítica" tem evitado que pensadores lancem mão das tradições estadunidenses e confirmado o sentimento de superioridade teórica europeia. Uma crítica desse mito é de vital importância para meu próprio trabalho, já que considero altamente importante fazer uso dos temas da tradição pragmatista americana em áreas da filosofia e da 
ciência social. Mesmo aqueles que se localizam nas fileiras da "Teoria Crítica" só têm a ganhar numa discussão com o pragmatismo, tanto em aspectos empíricos quanto normativos.

A relação entre as duas tradições intelectuais pode ser melhor investigada estabelecendo qual imagem da America prevalecia no Instituto de Pesquisa Social de Frankfurt depois de sua migração para Nova Iorque. É uma questão pertinente em que extensão a "Teoria Crítica" considerou os detalhes da vida política e social americana, ou levou em conta as realizações americanas na filosofia e nas ciências sociais. Ao responder a essa questão, não desperdiçarei o tempo do leitor com fatos bem conhecidos de tipo mais biográfico que essencial, tal como, por exemplo, o extenso auto-isolamento da Escola de Frankfurt vis-à-vis os bosques da academia americana com a atitude e conduta expressamente não conformistas de seus membros como acadêmicos europeus. Incidentalmente, Paul Lazarsfeld, que chegou aos Estados Unidos apenas poucos anos antes, mencionou sarcasticamente que, em comparação com Adorno, ele se sentia como um membro da Mayflower Society ${ }^{4}$. Mais importante que tais anedotas é uma avaliação dos escritos de seus membros. Isso não foi realizado - até onde eu sei - até agora, nem do ponto de vista que diz respeito à América nem com referência à extensa seção de revisão na revista da Escola, a Zeitschrift für Sozialforschung (Estudos em Filosofia e Ciência Social).

A hipótese teórica básica que os membros da Escola de Frankfurt levaram com eles quando migraram pode ser caracterizada grosseiramente como segue: o capitalismo liberal se fundamenta ostensivamente em um processo inexorável de transição para as formas monopolista e regulada pelo Estado. Eles argumentaram que, como resultado, o Estado liberal estava sendo transformado em sua contraparte autoritária e leis de natureza geral estavam sendo tematizadas para mudarem funcionalmente e, crescentemente, serem substituídas por regulações especiais. Esses processos foram acompanhados tanto pela destruição das condições para a individuação verdadeira, como por crescente desintegração de toda a alta cultura em favor da cultura de massa comercial e propagandista. Os diferentes níveis desse diagnóstico foram interconectados por meio de um inabalável funcionalismo. Isto é, mudanças psicológicas e culturais foram, desde o princípio, interpretadas como funcionais para a política, e esta foi funcional para a centralização econômica da dominação. Pelo menos entre o círculo interno dos membros da escola, a América e as experiências que eles lá tiveram depois de sua emigração não os levou a uma revisão dessas hipóteses. Para eles, a América era o capitalismo em sua forma pura. Consequentemente, os traços derivados do 
desenvolvimento do capitalismo na Alemanha tiveram que se manter válidos com severidade para os Estados Unidos. Toda e qualquer experiência pela qual passaram era apenas uma confirmação dessa hipótese prévia: nos Estados Unidos a pesquisa social se tornou, assim eles acreditaram, puramente uma pesquisa de contrato instrumental, e a filosofia nada além de uma redução positivista de todas as questões à metodologia; a psicologia social americana promoveu meramente o conformismo; e a cultura de massa representou perda e decadência dos poderes transcendentes da alta cultura europeia. Tomado como um todo, o exposto acima fez a socieade do New Deal aparecer como um totalitarismo nascente. Mesmo a formulação, frequentemente usada pelos membros da Escola de Frankfurt, de que eles estavam se esforçando para relacionar ideias europeias e métodos americanos é reveladora, pois implicitamente ignora a possibilidade de existirem ideias americanas importantes. Desejo demonstrar aqui, mesmo que brevemente, a relevância dessas ideias americanas como uma alternativa à teoria crítica em algumas áreas.

O mito positivo da "Teoria Crítica" é complementado pelo mito negativo do caráter empírico exclusivamente utilitário do pensamento americano. Mesmo que se encontre frequentemente, nas várias fases da história americana, uma sonora e explícita busca por novos modelos práticos e teóricos para a configuração das comunidades. As formas dessa busca se estendem desde os ideais comunais e fraternos do puritanismo, por meio de um misticismo da natureza, passando pelo catolicismo e por experimentos utópicos, até a mistificação do passado colonial ou das antigas condições no Sul. A tradição republicana clássica da America é, claramente, a que se faz mais importante dentre estas; ela funda, no final do século dezenove, uma expressão nova e contemporânea na filosofia do pragmatismo, na medida em que os ideais de autoadministração comunal formaram o ponto de partida para uma nova compreensão das soluções para problemas cognitivos e morais. Essa filosofia iniciou uma "revolta contra o formalismo"5 em toda a área das ciências sociais e na discussão pública nos Estados Unidos - ainda que mais na forma de estudos exemplares que em sínteses teóricas. Todavia, isso não pode ser descartado como mera pesquisa social que é reduzida à precisão metodológica ou desconectada dos problemas teóricos. Um dos principais objetos da crítica de Horkheimer foi precisamente esse pragmatismo: não apenas em muitos de seus ensaios, mas sobretudo em seu livro $O$ Eclipse da Razão, que apareceu na Alemanha com o título Zur Kritik der instrumentellen Vernunft ("Sobre a Crítica da Razão Instrumental”)". Ele se baseia em grande parte, entretanto, no oportuno livro de Max Scheler, no qual o pragmatismo aparece como uma filosofia que reduz a vida humana ao trabalho e é, portanto, 
inadequado para um retrato do que é autenticamente espiritual ou pessoal ${ }^{7}$. Nesses trabalhos, Horkheimer, assim, continua a tradição de décadas da arrogante e superficial repreensão alemã à corrente mais engenhosa do pensamento americano. A interpretação de Scheler se adequa à tentativa de Horkheimer de tratar o pragmatismo por toda parte como o irmão inconsistente do positivismo lógico. Eu não vou me estender aqui sobre o fato de que a apresentação de Horkheimer do positivismo lógico ${ }^{8}$ também foi completamente insuficiente, e que o representante mais importante de uma abordagem que surgiu próxima ao círculo positivista, mas desenvolveu seu próprio caminho, não foi considerado pela Escola de Frankfurt: Ludwig Wittgenstein.

A concepção de Horkheimer foi instilada pela seguinte lógica: ele procede de uma distinção entre razão objetiva e subjetiva. Um comportamento é subjetivamente racional, ele afirma, quando se preocupa meramente com a escolha de meios adequados economicamente ou tecnicamente para alcançar fins. No processo, os próprios objetivos são colocados em uma esfera não sujeita à reflexão; então, Horkheimer continua, a primazia da autopreservação do sujeito afirma-se sem ser percebida. Com isso, padrões de objetivos não elevados passam a existir. A razão instrumental ou subjetiva se tornou dominante desde o começo da modernidade - em particular, contudo, desde a crítica Iluminista da religião e definitivamente na sequência da morte de Hegel. Consequentemente, Horkheimer julga que ela destruiu a "razão objetiva", o conhecimento dos bens temporais mais elevados da humanidade, acima e além da autopreservação e do cálculo de utilidade. Ele afirma, ainda, que tal objetivo da razão claramente não poderia ser restaurado sob o disfarce de uma nova metafísica. Todavia, Horkheimer reivindica estar apto a se referir ao seu próprio projeto, que ele chama de "dialético", como esta razão objetiva, a racionalidade dos fins em si mesmos. Nesse contexto, o conceito de "positivismo" se torna um grito de guerra na totalização da razão subjetiva. Sob esse termo, o pensamento pragmatista é subsumido sem muito alvoroço; a pesquisa social empírica como um todo também cai mais e mais sob o mesmo veredito, sem muita consideração às suas várias formas ou ao possível falso entendimento de si mesma.

Adorno adotou uma abordagem significativamente mais cautelosa diante de tal estilização da "razão objetiva". Ele estava bem consciente ${ }^{9}$ de que deixaria uma impressão dogmática simplesmente contrastar uma razão objetiva "verdadeira" com uma progressiva subjetivação e instrumentalização da razão, e que proceder de tal forma não seguiria as regras do desenvolvimento dialético e da negação determinada. Assim, o dogmatismo da "razão 
objetiva" não apareceu na Dialética do Esclarecimento, que foi escrita por Adorno e Horkheimer juntos - embora esse fato tenha sido pago com ambiguidade teórica. Adorno, entretanto, também estava certo de que pragmatismo e positivismo deveriam ser vistos como totalizações da razão instrumental. Herbert Marcuse era um pouco mais aberto ao pragmatismo em suas resenhas dos livros de John Dewey, publicadas em Zeitschrift für Sozialforschung ${ }^{10}$. Ele admitiu que Dewey rejeitou o positivismo lógico, e que ele não advogou por um pensamento livre de valores em sua teoria do valor. Ao contrário, de fato Dewey fez um esforço para indagar sobre a racionalidade possível dos valores e, particularmente, para encontrar uma nova visão da constituição dos valores na ação humana. Esses aspectos construtivos dos esforços de Dewey, entretanto, permaneceram despercebidos pelos representantes da Escola de Frankfurt. Isso é ainda mais surpreendente quando se tem em mente que as concepções de Dewey foram publicadas em seu grande livro sobre experiência estética, e em seu estudo sobre a experiência religiosa, exatamente na mesma época e lugar em que Horkheimer e Adorno estavam trabalhando, em meados dos anos trinta na Universidade de Columbia em Nova York ${ }^{11}$.

Essa má compreensão do pragmatismo pode ser demonstrada mais vividamente com o uso do conceito de "adaptação". Os escritos dos membros da Escola de Frankfurt, por exemplo o ensaio de Adorno sobre Veblen, estão crivados de polêmicas contra o suposto caráter conformista e de darwinismo social do conceito de "adaptação". Primeiro, eles falharam em reconhecer que os pragmatistas fizeram distinções entre muitos tipos diferentes de adaptação; incluindo desde a "acomodação" passiva aos fatos ambientais dados, via "adaptação" ativa, no caso da transformação do mundo em um ambiente de vida útil, até a reconstrução de toda a personalidade em uma experiência religiosa ("ajustamento"). Mas, sobretudo, eles falharam em reconhecer que o conceito pragmatista de "adaptação" nunca significou rotina e perda de subjetividade, mas inovação prática, soluções criativas para problemas reais.

\footnotetext{
A teoria pragmática da inteligência entende que a função da mente é projetar novas e mais complexas finalidades - para libertar a experiência da rotina e do disfarce [caprice]. Não o uso do pensamento para realizar propósitos já dados, quer no mecanismo do corpo, quer naquele do estado da sociedade existente, mas o uso da inteligência para libertar e agir de forma livre é a lição pragmática. (John Dewey, $1917)^{12}$.
}

Os estudos sociológicos clássicos conduzidos por Thomas e Park - membros da Escola de Chicago -, consequentemente, se concentraram, precisamente, não na adaptação de 
imigrantes no sentido de sua americanização padronizada, mas sim na reorganização criativa da vida comunitária, por exemplo, pelos camponeses poloneses em Chicago ${ }^{13}$, e na realização da democracia sob condições de heterogeneidade cultural e étnica. $\mathrm{O}$ foco central não foi a decadência da comunidade a partir de alguma perspectiva cultural pessimista, mas a formação gradual de novas instituições. A teoria de Dewey sobre arte e religião lidou com a criatividade coletiva na constituição de valores ideais e com a criatividade individual na especificação “abdutiva”, não dedutiva, desses valores como metas da ação. No caso de Dewey, exatamente o oposto da má interpretação instrumentalista é o verdadeiro. Aqui, não é a técnica, mas a experiência estética que se faz crucial porque, se referindo a esta, Dewey pôde demonstrar a possibilidade tanto de um mundo pleno de significado que pode ser percebido sensitivamente como de tentativas criativas para imbuir aquele mundo com significado via apropriação criativa das possibilidades para a idealidade contida nele. Ao passo que, em outras palavras, os membros da Escola de Frankfurt anelaram desamparadamente por alguma noção passada de razão objetiva em suas críticas da razão instrumental, ou emaranharam-se nas ambiguidades do conceito de razão contido na expressão da dialética do Esclarecimento, o pragmatismo americano cresceu entre todas aquelas filosofias da história baseadas em uma metafísica da razão e desenvolveu uma teoria da constituição intersubjetiva de valores experimentados como significativos e vinculativos.

Essa diferença na filosofia social tem um paralelo no nível da teria política. No caso dessa última, as intepretações incorretas da Escola de Frankfurt sobre a América se basearam em uma compreensão marxista do liberalismo e da democracia. Eles foram concebidos, à maneira do marxismo ortodoxo, como superestrutura do capitalismo nos ensaios publicados antes da imigração do Instituto. Nessa leitura, a transição do capitalismo liberal para o monopolista é acompanhada da emergência do Estado totalitário como um pingente deste - o fascismo é interpretado como a dominação do capital monopolista. Em seu ensaio de 1934 sobre "A luta contra o liberalismo na concepção totalitária de Estado", Marcuse forneceu o que foi em parte uma crítica esplêndida das teorias nacionais socialistas nascentes da lei e do estado; ainda que seu principal argumento tenha sido de que foi o liberalismo que “'engendrou' de dentro de si mesmo o estado autoritário-totalitarista como seu próprio aperfeiçoamento a um nível mais avançado de desenvolvimento" ${ }^{14}$. Todos os elementos da democracia liberal, tais como a liberdade de expressão, de imprensa e de publicidade, tolerância, parlamentarismo e a divisão de poderes são expressamente reduzidos a componentes funcionais do capitalismo concorrencial. Enquanto em imigração, a Escola de 
Frankfurt produziu apenas umas poucas análises das tendências de desenvolvimento econômico nas sociedades ocidentais. Horkheimer e Adorno falaram muito globalmente de um "estatismo integral" que estava em formação, e depois de um "mundo administrado". Seus pontos de referência originalmente positivos - "economia planejada" e "proletariado" - foram discretamente deixados de lado. As esperanças a eles conectadas foram abandonadas e as insinuações sobre o sujeito da história e uma ordem social razoável foram substituídas por uma visão profundamente pessimista de uma duradoura dominação totalitária, na qual sobretudo judeus teriam que sofrer como objetos do poder. Especialmente no ensaio de Horkheimer de 1939, "Die Juden und Europa" ("Os judeus e a Europa") ${ }^{15}$, onde ele mais significativamente mudou seu foco nessa direção, o diagnóstico é repetido com uma ferocidade cortante: o totalitarismo é visto como um resultado do capitalismo, que teve, por necessidade, de perder sua forma liberal. "O novo antissemitismo é o precursor de uma ordem totalitária para a qual a ordem liberal se desenvolveu. É necessário revisitar as tendências do capital". Aqueles que não abandonaram a esperança de "que em algum lugar a reforma do capitalismo se realize mais suavemente que na Alemanha"16 foram rejeitados com desprezo. Mesmo as mais terríveis consequências do Nacional Socialismo foram tomadas por peças de evidência para a validade imutável da crítica marxista do capitalismo. Isso continha um partidarismo político secreto que levou Marcuse, mesmo depois do final da Segunda Grande Guerra, a falar da iminente fascistização dos Estados Unidos e da necessidade de criticar a social democracia mais fortemente que a União Soviética ${ }^{17}$. Esses indicadores não intencionam, naturalmente, uma denúncia política, nem uma tentativa de minimizar os perigos de um autoritarismo latente ou manifesto no ocidente, mas, ao invés disso, buscam demonstrar a inabilidade da "Teoria Crítica" para fazer justiça conceitual à administração da profunda crise social e econômica dos anos trinta na estrutura das sociedades com constituições democráticas. Reconhecidamente, existiram também vozes diferentes; Franz Neumann e Otto Kirchheimer diferem do círculo interno da Escola no que diz respeito à análise das democracias ocidentais e em seus diagnósticos do Nacional Socialismo. Foi sobretudo Neumann quem sempre defendeu a primazia política da manutenção da democracia ${ }^{18}$. Em sua crítica a Carl Schmitt, ele se tornou consciente do caráter problemático de uma interpretação marxista-funcionalista do parlamentarismo e do estado constitucional. Politicamente, ele certamente simpatizou com a linha da política americana de Wilson a Roosevelt; ainda que em termos teóricos ele nunca tenha superado o funcionalismo, adicionou a este, entretanto, declarações sobre o valor ético intrínseco das instituições democráticas, da 
divisão de poderes e da independência do judiciário. Neumann, no entanto, não colocou as fontes históricas e a lógica independente dessas tradições em uma relação consistente com a crítica marxista do liberalismo. Ele nunca revisou sua tese sobre a mudança na função da lei.

Tal abordagem marxista-funcionalista não poderia fazer justiça à tradição democrática americana. Se liberalismo e democracia são igualados com o utilitarismo, isso deprecia precisamente a linha de batalha central, junto à qual conflitos sobre a autocompreensão da América sempre foram conduzidos. Desde o século dezoito, o que deve ser, no mínimo, chamado de tensão existiu entre os polos utilitarista e republicano-normativista do pensamento americano. $\mathrm{Na}$ história da América, as fontes nativas foram exploradas repetidamente para manter o individualismo possessivo dentro de limites razoáveis. Exemplos são o populismo agrário, depois da guerra civil, tendências reformadoras do progressismo social, antes da Primeira Grande Guerra, e o New Deal. Teóricos sociais tão diferentes entre si, como John Dewey e Talcott Parsons, estão unidos nessa batalha contra o utilitarismo. Nem o influente estudo de Parsons sobre A estrutura da ação social ${ }^{19}$ nem a filosofia política de Dewey foram sequer reconhecidos pelos Teóricos Críticos. Qualquer relação entre política e teoria da ação teve que, necessariamente, colidir com seus temas marxistas-funcionalistas. O pensamento político de Dewey, entretanto, procedia precisamente dos processos de ação coletiva e não do Estado ${ }^{20}$. Tal ação encontra problemas - assim segue seu argumento - e tem consequências não intencionais, ou não antecipadas, que o coletivo ativo, então, deve processar reflexivamente. A comunicação entre todos os participantes desempenha um papel substancial nesse processo de interpretação e avaliação das consequências. O programa político de Dewey está voltado para a recriação da esfera pública democrática em perigo, a revitalização da vida comunitária, mesmo em cidades grandes, prevenindo o desenvolvimento da "expertocracia" 21 , tornando a esfera pública responsável pela recepção de consequências não intencionais que a sociedade industrial produz, por meio da publicidade e liberdade de pesquisa nas ciências sociais. Não é possível avaliar esse programa adequadamente aqui. É vital, no entanto, enfatizar que, com sua redução de democracia a capitalismo, a Escola de Frankfurt obliterou um dos mais importantes temas da discussão contemporânea sobre a teoria no Ocidente e no Oriente: nomeadamente, a questão sobre afinidade ou tensão entre essas vertentes do desenvolvimento social moderno.

$\mathrm{Na}$ área da psicologia social, a tradição pragmatista americana e a Escola de Frankfurt também se confrontaram. Numerosos estudos foram inspirados por Cooley, Mead e Dewey 
nos quais - por meio dos conceitos de "assumir papel" (role-taking), de Self, de Outro generalizado e interação simbólica - o desenvolvimento do Eu foi abordado como resultado de uma interação social. Tais pesquisas contrastaram bruscamente com qualquer reducionismo psicológico behaviorista e, por sua vez, inspiraram várias tentativas de integrar a psicologia social interacionista com a psicanálise. Com uma exceção, os membros da Escola de Frankfurt - todos foram decisivamente influenciados pela psicanálise - reagiram a esse correlato sociopsicológico da tradição democrática americana, rejeitando-o nos termos mais nítidos. Aqui, a exceção foi Erich Fromm. Embora ele tenha começado como um marxista funcionalista e tenha tentado traçar uma linha entre estruturas sociais e libidinais, depois, tornou-se cada vez mais cético em relação à teoria freudiana dos impulsos. Durante sua imigração, ele se esforçou por integrar a psiquiatria interpessoal de Harry Stack Sullivan e a antropologia cultural de Ruth Benedict e Edward Sapir. Isso não implicou em uma revisão consistente da teoria dos impulsos. Fromm, no entanto, pelo menos rompeu com o funcionalismo marxista de seus amigos, e isso bastou para que eles o excomungassem do círculo sob acusações de revisionismo. Em 1936, Adorno, com desprezo, o aconselhou a ler Lenin urgentemente, para reencontrar a si mesmo lidando com perigos conformistas $^{22}$. A virada de Fromm, mais expressivista que interacionista, foi entendida por Horkheimer e Adorno como indicativo de que ele estava preparado a se conformar a uma ordem social que, na visão deles, necessitava de uma revolução. Eles eram obrigados a pensar assim, já que fecharam os olhos para os conteúdos idealizadores da democracia. Como consequência, consideraram a esfera da intersubjetividade compreendendo mais conformidade $\mathrm{e}$ conformismo, esperando que mudanças radicais pudessem vir da força indomável dos impulsos instintivos. Consideremos que, nos anos após a guerra, Horkheimer retornou ao pessimismo schopenhaueriano de seus anos iniciais, e Marcuse afiou o seu freudismo até um ponto mais radical, transformando-o em uma justificativa para a revolução baseada em uma metafísica já não da razão, mas dos impulsos instintuais. Em seu livro de 1955, Eros e civilização, ele polemicamente atacou Sullivan e Fromm a partir dessa posição ${ }^{23}$. Enquanto Fromm devotou sua atenção ao destino da espontaneidade humana na sociedade da época, Horkheimer e Adorno podiam apenas perceber a destruição de toda espontaneidade. Em 1940 eles estavam para afirmar que testemunharam "uma mudança que transforma os homens em simples centros passivos de reação, em sujeitos de 'reflexos condicionados' porque não têm mais centros de espontaneidade, não têm mais medida obrigatória de comportamento, nada que transcenda o mais imediato de seus desejos, necessidades e aspirações" ${ }^{24}$. Eles, então, 
assumiram o behaviorismo como uma descrição dos fatos, mas consideraram uma psicologia da criatividade e da interpessoalidade como um mero disfarce ideológico envolvente. Nenhuma análise poderia estar mais distante da verdade! Isso por três motivos: primeiro, não faz justiça à realidade da América, a qual, em palavras de Max Weber, não era "uma disforme montanha de areia de indivíduos, mas uma confusão de associações estritamente exclusivas e voluntaristas" $^{25}$. Segundo, também falhou em lidar apropriadamente com a tradição dominante na era pós-guerra, em que cada vez mais pessoas adotaram em grau sempre crescente uma compreensão de si mesmas em termos de individualidade criativa. Terceiro, a rapidez e falsidade desse diagnóstico indica a lacuna da psicologia social dentro da "Teoria Crítica", que poderia reivindicar fazer mais que meramente mediar diretamente entre leis supostamente político-econômicas e irracionalidade individual. Mesmo o grande estudo sobre a "personalidade autoritária" foi danificado, como Herbert Blumer enfatizou, pelo fato de que nele os tipos psicológicos estavam apenas correlacionados com comportamento político, e o possível surgimento de um movimento social tal como o nazismo não foi analisado em termos de teoria da ação ${ }^{26}$. Não existiam meios conceituais para a análise de processos sociais nos quais pessoas de diferentes estruturas de personalidade interagem e se juntam para formar grupos ou organizações. Essa deficiência também abarca a teoria da socialização em seu sentido mais estreito, como o estudo do estágio formativo das estruturas de personalidade. Sobretudo, foi a crítica feminista que, em anos recentes, trouxe à tona a falsidade das premissas psicanalíticas ortodoxas na conexão com o ganho de autonomia e aprendizagem do papel de gênero ${ }^{27}$. Essas premissas, no entanto, formaram a base das exposições da Escola de Frankfurt sobre os perigos de um progressivo enfraquecimento da autoridade paterna e sua substituição pela burocracia e indústria cultural. A abordagem das relações de objeto retornando a Sullivan - especialmente destaca, como alternativa, a importância da percepção intersubjetiva e do reconhecimento para o desenvolvimento da criança. Por isso, chega a teses completamente diferentes: a autoridade paterna não simplesmente se desintegrou, mas está transformada em uma crescente participação na educação infantil e em uma maior autonomia da personalidade materna. "Em todo o caso, hoje tanto os pais reais como o pai ideal promovidos pela mídia são muito mais devotados às obrigações parentais, começando com o nascimento da criança, do que eles foram no passado" 28 . Correspondentemente, não há razão para se falar em um clima familiar cada vez mais frio e sobre crianças mais propensas à manipulação. 
Os membros da Escola de Frankfurt não conceberam, portanto, a mediação entre as demandas sociais e a psique individual em categorias de uma teoria sociológica da ação. Em vez disso, foi utilizada uma teoria da cultura que era, entretanto, concebida em termos cada vez mais estreitos e logo focada exclusivamente na arte autônoma e, frequentemente, esotérica $^{29}$. A partir do ponto vantajoso que isso oferece, o olhar crítico dos membros repousou sobre a mídia e seus conteúdos na cultura de massa americana. Os pronunciamentos de Adorno sobre o jazz, sobre a recepção da música séria no rádio e sobre as grandes reuniões esportivas foram devastadores ${ }^{30}$. A única conclusão a que ele chegou em seus estudos foi a de que os receptores foram condenados, em todas essas áreas, a serem tritões passivos e irreflexivos, para usar seus termos, numa prefiguração de um totalitarismo nascente. Ele não parece ter sido perturbado pelo fato de que o totalitarismo tendeu a surgir em áreas caracterizadas por uma ausência da cultura de massa moderna ${ }^{31}$. Pesquisas empíricas sobre comunicação de massa e sociologia da cultura dificilmente teriam confirmado qualquer de suas análises. Não desejo minimizar os possíveis problemas da cultura de massas, mas sim afirmar que Adorno não os demonstrou, preferindo, em vez disso, prejulgá-los teoricamente. A teoria social da Escola de Frankfurt não possibilitou que a nova mídia e a cultura popular tivessem, em primeiro lugar, qualquer efeito positivo em uma sociedade democrática.

Não é preciso compartilhar as esperanças excessivamente utópicas de Walter Benjamin em um potencial cultural revolucionário das novas formas de arte tecnológicas para ver que a referência da crítica de Adorno, em cada caso, foi a alta cultura de uma época passada, ou a obra-prima singularmente perfeita, e não a cultura popular ou de massa daqueles tempos $^{32}$. A comparação com a própria crítica cultural americana é óbvia, quando Adorno vê nos ataques polêmicos de Veblen ao notável consumo da "aula de lazer" nada além de inveja dos últimos recursos contra as forças do conformismo. O refinamento burguês, determinado a esperar por uma revolução que acabe com toda exploração, incompreensivelmente confronta um talvez ingênuo igualitarismo e a adoção de um "instinto de artesão" rural e urbano no pensamento americano.

Consequentemente, o relacionamento entre "Teoria Crítica", a América e suas tradições intelectuais permaneceu improdutivo pelos vários campos do pensamento. O que foi completamente diferente nos casos de outros imigrantes - de Hannah Arendt a Alfred Schütz. A justiça histórica, porém, requer que mencionemos que o retorno para a Alemanha levou Horkheimer e Adorno a uma revisão na direção exata que se poderia esperar da conexão com 
suas imigrações. Em uma espécie de retrospectiva autobiográfica no texto "Wissenchaftliche Erfahrungen in Amerika" ("Experiências Científicas na América"), Adorno fala da "ausência de respeito pela intelectualidade"; e explica que isso possibilitou a ele se libertar da crença nos mandarins da cultura alemã, que ele pôde desenvolver uma abertura para o Iluminismo e para a pesquisa empírica, e que experimentou numa substancial democracia "um potencial humanitário real que dificilmente poderia ser encontrado na velha Europa" ${ }^{33}$. Entre os projetos de Horkheimer e Adorno para a tradução de livros americanos pode-se encontrar o nome de John Dewey; mas o plano nunca veio à existência. No entanto, essa autorrevisão foi apenas parcial. No mesmo fôlego com o qual Adorno comenta sobre a substância democrática da América e, a partir dela, sua possível imunidade contra o totalitarismo, ele novamente nomeia a sociedade capitalista americana como forma pura do capitalismo. Além disso, seu veredito contra o "positivismo" das várias linhas de pensamento permeneceu sem revisão. Também Herbert Marcuse, que não retornou para a Alemanha, manteve a estilização da "Teoria Crítica" como a única alternativa ao positivismo totalizado. Cada vez mais, esse sentimento solitário de superioridade teórica e missão intelectual se tornou uma barreira contra a recepção de outras tendências intelectuais. Seja nos casos de Wittgenstein ou Dewey, Durkheim ou Parsons, os membros da Escola de Frankfurt ou rejeitaram ou não responderam a qualquer uma das grandes inovações da teoria social no vigésimo século.

Por essas razões, o empreendimento de Jürgen Habermas de abertura da "Teoria Crítica" para esses impulsos não pode ser superestimado. A diferença que levou adiante reside não apenas em várias modificações, mas numa atitude geralmente diferente para a construção da teoria e prática de pesquisa nas ciências sociais, também no marxismo. Reflexões sobre a imagem da Escola Escola de Frankfurt sobre a América podem parecer supérfluas para aqueles que consideram o trabalho de Jürgen Habermas a síntese bem sucedida das tradições americana e frankfurtiana. Em um lugar diferente dei extensos motivos pelos quais eu recomendo cuidado com tal consideração, e ainda vejo elementos do pragmatismo que superam os empreendimentos de Habermas ${ }^{34}$. Por mais ressonantes que as discussões de Habermas sobre os trabalhos de Charles Peirce e George Herbert Mead possam ser, ele nunca fez uma interpretação completa de seu relacionamento com o pragmatismo. A lacuna mais óbvia se relaciona a John Dewey, que é dificilmente mencionado. O antigo livro de Habermas, Strukturwandel der Öffentlichkeit, que lembra fortemente Dewey, não obstante, contém ao mesmo tempo a perspectiva do "mundo administrado"35. Foi essa herança que levou Habermas à sua recepção - crítica - da teoria dos sistemas de Luhmann e à adoção da 
tese sobre a existência de esferas de ação livres de normas como encontramos em seu principal trabalho, Teoria do Agir Comunicativo. A crítica da teoria da ação de Habermas vem de diferentes pontos de vista. Por exemplo, Arnason pensa que esta teoria, em sua forma atual, é limitada por uma adaptação antecipada da teoria dos sistemas de Luhmann ${ }^{36}$. Por isso, ele afirma que as revisões de Habermas no campo da teoria da história resultam em uma estrutura quase teleológica que contém apenas a interação das lógicas do sistema, mas não a abertura genuína da história. Alexander, por outro lado, faz a crítica de que Habermas não descobriu realmente uma teoria da sociedade na base de um conceito de ação não instrumentalista, mas gerou uma categoria residual de ação não comunicativa para propor uma descrição parcialmente não normativa da vida moderna no estilo da "Teoria Crítica"37. Antonio vê uma conexão entre a busca não pragmatista por uma razão normativa transhistórica no trabalho de Habermas e suas tendências para um formalismo ético ${ }^{38}$. Em suma, Habermas usa motivos do pragmatismo apenas para uma continuação intersubjetivista das teorias da racionalização weberiana e marxiana.

Uma teoria da criatividade da ação corresponderia mais de perto ao pragmatismo e substituiria os debates sobre o fim do indivíduo por uma investigação sobre as estruturas sociais da criatividade individual. Estou pensando aqui em todo o espectro da participação política e cultural, por meio da criatividade tornada "yuppie", na violência espontânea como manifestação de uma expressividade bloqueada e submersa. Uma reavaliação ética de laços primários e pesquisas empíricas sobre os recursos para a formação de comunidades - tal como os que vêm sendo conduzidos por Robert Bellah - tomariam o lugar do universalismo formal da ética do discurso ${ }^{39}$. Bellah percebe o potencial que as tradições bíblica e republicana oferecem para superar o individualismo expressivo e utilitário na vida privada e profissional, comunal e nacional na América. Devemos, em contraste, procurar, via análise comparativa, os equivalentes alemães e, pelo engajamento em debates críticos com teses modistas sobre individualização, acessar o alcance dessa potencialidade. Um estudo sobre a extensão com que as sociedades fazem de suas próprias diferenciações funcionais o objeto da formação da vontade democrática poderia, então, substituir uma demarcação fixa entre sistema e mundo da $v$ vida $^{40}$. Em uma época na qual a questão da natureza da democracia provou ser o eixo substancial de debates políticos ao redor do mundo é absurdo negligenciar os instrumentos teóricos e empíricos a serem encontrados na história e no presente estado das ciências sociais americanas. Em nenhum outro país uma marca tão profunda foi deixada no pensamento por 
uma compreensão que vê a realidade do dia como aquela de uma sociedade democrática. Em minha opinião, ainda não foi sentido o impacto completo desses instrumentos conceituais.

\section{NOTAS}

1 Publicado originalmente em Symbolic Interaction 15, no. 3: 261-75, 1992. Tradução de Carlos César Barros.
Publicação autorizada pelo próprio Hans Joas, a quem agradecemos profundamente.
2 Ernst Troeltsch Professor de Sociologia da Religião na Humboldt-Universistät zu Berlin.
3 Cf. sobretudo Rolf Wiggershaus, Die Frankfurter Schule. Geschichte-theoretische Entwicklung-politische
Bedeutung (München, 1986) [A Escola de Frankfurt. História, desenvolvimento teórico, significação política
(Difel, 2002)]. Meu ensaio deve muito a esse excelente livro. Rolf Wiggershaus também comentou uma versão
anterior deste ensaio. Sou grato por sua crítica e pelos comentários de Hans-Joachim Dahms (Göttingen) e Ricca
Edmondson, Galway (Irlanda).
4 Paul Lazarsfeld, "An Episode in the History of Social Research: A Memoir”, em Donald Fleming e Bernard
Bailyn, eds., The Intellectual Migration: Europe and America 1930-1960 / Cambridge, Mass., 1969, p. 301. [A
sociedade Mayflower foi formada pelos descendentes dos que chegaram aos Estados Unidos em 1620, em navio
com o mesmo nome].
5 Esse é o subtítulo de um livro de Morton White, Social Thought in America (Boston, 1947). Cf. Também Darnell Rucker, The Chicago Pragmatists (Minneapolis, 1969).

6 Max Horkheimer, The Eclipse of Reason (New York, 1947). [Eclipse da razão. Editora Unesp, 2016]. C. Wright Mills teve que escrever um memorando confidencial sobre o manuscrito desse livro para a Oxford University Press. Sua avaliação é muito próxima da minha. ("Francamente, entretanto, eu não vejo qualquer evidência de que Horkheimer tenha realmente se apropriado do pragmatismo, exceto [1] em uma forma um tanto vulgar e [2] nos últimos pronunciamentos dos escritores da Partisan Review, que ele tardiamente ataca. Ele não deveria dignificar o cenário o suficiente para tornar evidente seu conhecimento dessa literatura de, no máximo, ensaios menores de seguidores [...] suas observações [...], certamente, não dão segurança de que ele conhece os pragmatistas que está atacando". Veja J.L. Simich e Rick Tilman, "Critical Theory and Institutional Economics: Frankfurt's Encounter with Veblen”, em Journal of Economic Issues 14[1980], pp. 631-48).

7 Max Scheler, Erkenntnis und Arbeit: Eine Studie über Wert und Grenzen des pragmatischen Motivs in der Erkenntnis der Welt (Frankfurt, 1977). Originalmente publicado em M. Scheler, Die Wissenformen un die Gesellschaft (Leipzig, 1926).

8 Hans-Joachim Dahms, "Die Vorgeschichte des Positivismusstreits: von der Kooperation zur Konfrontation. Die Beziehungen zwischen Frankfurter Schule und Wiener Kreis 1936-1942”, em Jahrbuch für Soziologieschichte 1990, pp. 9-78.

9 Carta de Adorno a Löwenthal, 3 de junho de 1945 (Wiggershaus, p. 371 [p. 362 na edição brasileira]).

10 Herbert Marcuse, "Review of: John Dewey, Logic. The Theory of Inquiry, New York 1938", in Zeitschrift für Sozialforschung 8 (1939-40), pp. 221-28; e seu "Review of: John Dewey, Theory of Valuation, Chicago 1939", em Zeitschrift für Sozialforschung 9 (1941), pp. 144-48; uma interpretação mais extensa, mas também mais negativa, dessas resenhas pode ser agora encontrada em Hans-Joachim Dahms, Positivismusstreit. PhD Dissertation (Göttingen, 1990), pp. 76-82.

11 John Dewey, Art as Experience (New York, 1934) [Arte como experiência. Martins Fontes, 2010]; Dewey, A Common Faith (New Haven, 1934). Há agora uma excelente interpretação do trabalho de Dewey de uma perspectiva de sua teoria da experiência estética: Thomas Alexander, John Dewey's Theory of Art, Experience and Nature: The Horizons of Feeling (Albany, 1987).

12 John Dewey, "The Need for a Recovery of Philosophy”, em Dewey et al., Creative Intelligence (New York, 1917), p. 63f.

13 Hans Joas, "Symbolic Interactionism", em Anthony Giddens e Jonathan Turner (eds.), Social Theory Today (Cambridge, 1987), pp. 82-115. [Interacionismo simbólico, em Teoria Social Hoje, Editora Unesp, 1999. pp. 127-174].

14 Herbert Marcuse, "Der Kampf gegen den Liberalismus in der totalitärien Staatsauffassung”, em Zeitschrift für Sozialforschung 3 (1934), pp. 161-95. [“O combate ao liberalismo na concepção totalitária do Estado”, em MARCUSE, H. Cultura e sociedade, v.1., Paz e Terra, 1997, pp. 47-88].

${ }^{15}$ Max Horkheimer, "Die Juden und Europa”, em Zeitschrift für Sozialforschung 8 (1939-40), pp. 115-37. 
${ }^{16}$ M. Horkheimer, p. 115: "Der neue Antisemitismus ist der Sendbote der totalitären Ordnung, zu der die liberalistische sich entwickelt hat. Es bedarf des Rückgangs auf die Tendenzen des Kapitals."; p. 116: "daß irgendwo die Reformierung des westlichen Kapitalismus glimpflicher sich abspielt als die des deutschen."

${ }^{17}$ Wiggershaus, p. 432 e p. 435. [na edição brasileira, p. 423 e p. 426].

${ }^{18}$ Franz Neumann, "Der Funktionswandel des Gesetzes im Recht der bürgerlichen Gesellschaft", in Zeitschrift für Sozialforschung 6 (1937), pp. 542-96. Para suas experiências na América, ver Neumann "Intellektuelle Emigration und Sozialwissenchaft", in Neumann, Wirtschaft, staat, Demokratie: Aufsätze 1930-54 (Frankfurt, 1978), pp. 402-23.

19 Talcott Parsons, The Structure of Social Action (New York, 1937). [A estrutura da ação social. Editora Vozes, em dois volumes editados em 2010 e 2011, respectivamente].

20 John Dewey, The Public and Its Problems (New York, 1927).

21 "Expertocracy" em inglês, um governo de especialistas.

22 Carta de Adorno para Horkheimer, 21 de março de 1936 (cf. Wiggershaus, p. 184 e p. 299 [p. 190 e p. 295 na edição brasileira]).

23 Herbert Marcuse, Eros and Civilization (Boston, 1955). [Eros e civilização: uma interpretação filosófica do pensamento de Freud. LTC, 1999].

${ }^{24}$ Sugestão de Adorno para carta de Horkheimer endereçada a Robert Hutchins (cf. Wiggershaus, p. 308 [na edição brasileira, de onde reproduzimos a tradução, p. 303]). Um texto altamente importante para qualquer interpretação da relação de Adorno com a cultura americana e a crítica cultural americana é Theodor W. Adorno, "Veblen's Attack on Culture", in Zeitschrift für Sozialforschung (Studies in Philosophy and Social Sciences) 9 (1941), pp. 389-413. [“O ataque de Veblen à cultura” em Prismas: crítica cultural e sociedade, Editora Ática, 2001. pp. 69-90].

${ }^{25}$ Max Weber, "Die protestantischen Sekten un der Geist des Kapitalismus", em Gesammelte Aufsätze zur Religionssoziologie i, pp. 207-36; aqui, p. 215.

${ }^{26}$ Herbert Blumer, “Collective Behavior”, in Joseph B. Gittler (ed.), Review of Sociology (New York, 1957), pp. 127-58; aqui, p. 147.

${ }^{27}$ Jessica Benjamin, "Die Antinomien des patriarchalischen Denkens: Kritische Theorie und Psychoanalyse", em Wolfgang Bonß e Axel Honneth (eds.), Sozialforschung als Kritik (Frankfurt, 1982), pp. 426-55.

${ }^{28}$ J. Benjamin, p. 449.

${ }^{29}$ Cf. Axel Honneth, Kritik der Macht (Frankfurt, 1985), pp. 11-111. Esse capítulo é muito importante para o presente ensaio, particularmente sua tese de um déficit sociológico no programa original de Horkheimer e da derradeira "repressão do social" de Adorno. O mesmo é verdade para a brilhante elaboração de Honneth de uma ideia originalmente apresentada por Jürgen Habermas: Honneth, "Critical Theory", em Anthony Giddens e Jonathan Turner (eds.), Social Theory Today (Cambridge, 1987), pp. 347-82. [“Teoria Crítica” em Teoria social hoje. Editora Unesp, 1999, pp. 503-52]. Minha única objeção a esse ensaio é que Honneth exagera as diferenças entre o centro e a periferia da Escola de Frankfurt e, consequentemente, reivindica ideias para Neumann e Fromm que, realmente, não consigo encontrar elaboradas em seus escritos.

30 Theodor W. Adorno, Prismen (Frankfurt, 1955). [Prismas. Editora Ática, 2001].

${ }^{31}$ Leon Bramson, The Political Context of Sociology (Princeton, 1961), p. 129. Herbert Gans, "Popular Culture in America: Social Problem in a Mass Society or Social Asset in a Pluralist Society?", em Howard S. Becker (Ed.), Social Problems (New York, 1966, pp. 549-620). As perspectivas de Adorno foram vistas com mais simpatia por Douglas Kellner, "Kulturindustrie und Massenkommunikation: die Kritische Theorie und ihre Folgen", in Bonß e Honneth (ver nota 26), pp. 482-515; Martin Jay, "Adorno in Amerika", in Ludwig von Friedeburg e Jürgen Habermas (eds.). Adorno-Konferenz 1983 (Frankfurt, 1983), pp. 354-87.

${ }^{32}$ George Herbert Mead, "The Nature of Aesthetic Experience”, in International Journal of Ethics 36 (1926), pp. 382-92.

33 Theodor W. Adorno, "Wissenschaftliche Erfahrungen in Amerika," in Adorno, Schriften, vol. 10.2 (Frankfurt, 1977), pp. 702-38: "Abwesenheit des Respekts vor allem Geistigen"; "Potential realer Humanitat, das im alten Europa so kaum vorfindlich ist." ["Experiências científicas nos Estados Unidos" em Palavras e sinais: modelos críticos 2. Editora Vozes, 1995. pp. 137-78].

${ }^{34}$ Hans Joas, "The Unhappy Marriage of Hermeneutics and Functionalism," in Axel Honneth and Hans Joas (eds.), Communicative Action (Cambridge 1991), pp. 97-118.

${ }^{35}$ Jurgen Habermas, Strukturwandel der Offentlichkeit (Neuwied, 1962). Agora traduzido como The Structural Transformation of the Public Sphere (Boston, 1989). Com uma introdução para a nova edição alemã (Frankfurt 1990, p. 30) Atualmente Habermas faz uma autocrítica sobre esse ponto. [Habermas "Mudança estrutural da esfera pública: investigações sobre uma categoria da sociedade burguesa", Editora Unesp, 2011. (A edição brasileira conta com o prefácio de 1990)]

${ }^{36}$ Johann Pall Arnason, Praxis und Interpretation (Frankfurt, 1988). 
37 Jeffrey Alexander, "Habermas' New Critical Theory: Its Promise and Problems," in American Journal of Sociology 91 (1985-86), pp. 400-24

${ }^{38}$ Robert J. Antonio, "The Normative Foundations of Emancipatory Theory: Evolutionary versus Pragmatic Perspectives," in American Journal of Sociology 94 (1988-89), pp. 721-48.

${ }^{39}$ Robert Bellah et al., Habits of the Heart (Berkeley, 1985).

40 Hans Joas, "The Democratization of Differentiation," in Jeffrey Alexander e Piotr Sztompka (Eds.), Rethinking Progress (London, 1990), pp. 182-201. 